\title{
The first successful combined heart-lung transplantation
}

\author{
Bruce A. Reitz, MD
}

Everyone in the room was immediately captivated by the sight of the large and empty thoracic cavity after the complete heart-lung block had been removed from our recipient. It was March 9, 1981, and Drs Norman Shumway, John Wallwork, and I were in the midst of an operation that would result in a remarkable recovery for 45-year-old Mary Gohlke, who was in the end stages of primary pulmonary hypertension (PPH). The events that led up to this operation, as well as Mary's recovery and rehabilitation, are the subject of this brief personal reflection, invited by Journal Editor, Dr Lawrence Cohn.

Twelve years earlier, I had arrived in Dr Shumway's Stanford department as a senior medical student seeking a 6-month experience in the experimental laboratory. My timing was good. It was early June 1969, and the Stanford heart transplant program was well underway, directed by Drs Shumway and Edward Stinson, who together had performed the first adult human heart transplantation in the United States in January of 1968. There was, of course, a lot of excitement about heart transplantation in those years, and I was privileged to observe the 14th Stanford heart transplant and, more important, to work with Drs Stinson and Eugene Dong in the experimental laboratory of the department. Dr Shumway had always believed that new procedures and techniques that were going to be introduced in the operating room and in the care of patients should first be studied as well as possible in the experimental laboratory. Being able to assist Ed Stinson in the experimental laboratory as he performed heart transplants in dogs was an enormous privilege and showed me the way in which an extremely gifted surgeon went about performing meticulous and beautifully efficient operative procedures. There was no question after that experience that I wanted to be a cardiac surgeon. Two years later, I was able to return to Dr Shumway's team as a junior resident. This was a unique training philosophy whereby residents were introduced to cardiac surgery early after medical school, somewhat like the integrated cardiac surgery training programs of today.

As I finished the chief resident year in 1976 and subsequently finished 2 additional years of general surgery

\footnotetext{
From the Department of Cardiothoracic Surgery, Stanford University, Stanford, Calif. Address for reprints: Bruce A. Reitz, MD, Norman E. Shumway Professor Emeritus, Department of Cardiothoracic Surgery, Falk Cardiovascular Research Building, 300 Pasteur Dr, Stanford, CA 94305-5407 (E-mail: breitz@stanford.edu). J Thorac Cardiovasc Surg 2011;141:867-9 $0022-5223 / \$ 36.00$

Copyright (c) 2011 by The American Association for Thoracic Surgery doi:10.1016/j.jtcvs.2010.12.014
}

training for Board certification, I was able to return to the experimental laboratory part-time to work on the heart transplant projects currently underway. In a casual conversation, I asked Dr Shumway what needed to be done, and he said that he would like to see some progress in the possibility of combining heart transplantation with complete bilateral lung transplantation, inasmuch as there were patients with congenital heart defects and also patients with severe lung disease who currently were not able to be treated by transplantation. This led to some early heartlung transplants in dogs with Bill Baumgartner, MD. Technically successful, it turned out to be an unsatisfactory model, inasmuch as the respiratory pattern in dogs was severely altered after denervation. Then, as a young assistant professor in the department, I started to study heart-lung transplants in small rhesus and cynomolgus monkeys. These experiments were done with Nelson Burton, MD, and John Pennock, MD. In a short period of time, we had developed a reliable method for performing the heart-lung transplant in the small monkeys and achieved survivors with both autotransplantation and allotransplantation, although we did not use immunosuppression. Nevertheless, Dr Shumway was quite excited by the appearance of the monkeys, which were able to breathe normally and were normally active after complete heartlung transplants. It was fun for us when he would include the laboratory in his early morning rounds to check up on their progress.

Fortuitously, another significant event for the field of transplantation was developing in Europe at the time. A new immunosuppressive compound known as cyclosporin A had been identified in the laboratories of Dr Jean Borel and his colleagues at Sandoz Inc. This compound, after experimental and then clinical work by Professor Roy Calne and David White at Cambridge University, seemed to provide amazingly improved immunosuppression. In the summer of 1978, several months after the initiation of the clinical trial of cyclosporin A in patients undergoing renal transplants, David White visited Stanford and gave a seminar to a small group of the heart transplant team. From that meeting, Sandoz was contacted and agreed to provide the Stanford laboratory with enough of the precious powder for use both in rat heterotopic cardiac transplants and for the primate experiments of heart and heart-lung transplantation. At that time, the powder was dissolved in olive oil and given as an intramuscular injection. Little was known about the clinical use of the material, but it soon became apparent when administered to the monkeys that the immunosuppression was superior to that of previous drug therapies. 
It proved effective, allowed good healing of the tracheal anastomosis, and quick recovery of the animals to apparently normal pulmonary and heart function.

The results of the heart-lung transplant experiments were presented at the 60th Annual Meeting of The American Association for Thoracic Surgery in San Francisco in April of 1980. This presentation turned out to be important for two reasons. First, Drs Shumway, Stinson, and I believed that the growing experience of long-term survival with the primates provided the basis for a clinical trial. By early fall of 1980 , we began to think about potential patients. At the same time, the use of cyclosporine for the regular heart transplant patients was being organized, and the Food and Drug Administration (FDA) and the Stanford Institutional Review Board gave approval for that trial. The first heart transplant recipient to receive cyclosporine was operated on in December of 1980. He and subsequent patients continued to show improved postoperative recoveries that were clearly different from those of the previous patients receiving steroids and azathioprine.

Second, there were a few small newspaper accounts of the presentation from The American Association for Thoracic Surgery, describing the monkeys that had survived after heart and lung replacement. One of these articles appeared in the Mesa Tribune, in Mesa, Arizona, where the advertising accounts manager, Mary Gohlke, happened to see this article and immediately began to wonder whether it might help her. Over the previous several years, she had experienced a steady decline in her health and had been diagnosed with PPH. She had recently had to stop work and was now extremely limited. She had gone to Houston to consult with Dr Michael DeBakey, who confirmed her cardiologist's diagnosis and the information that there were no effective treatments for the disease. Someone on the Houston team had mentioned to Mary that perhaps the only treatment one could think about was to transplant the heart and lungs, but "that was impossible."

Mary's health was declining rapidly, she had two young teenage sons, and she was intrigued enough by the newspaper clipping that she picked up the telephone and called the Stanford Medical Center in the summer of 1980 and asked to speak to me. I told her what we had learned and that it was extremely experimental, but perhaps in the future, it might be able to help her. Several months later, she called again to say that her condition had worsened, and she wanted to know whether there was any chance that we might consider her for a transplant. So, in October, we arranged for Mary and her husband to come up to Stanford to meet with me and other members of the heart transplant team. After that meeting, we knew she would be an excellent candidate. Still, the heart transplant trial with cyclosporine had not yet been started and other administrative procedures needed to be resolved.
In our discussion about potential candidates, patients with PPH and Eisenmenger syndrome, particularly those without previous cardiac surgery, were thought to be ideal potential recipients. In $\mathrm{PPH}$, the right heart, right atrium, right ventricle, and pulmonary artery would be severely dilated and failing, and there would be a minimum of bronchial collaterals and potential adhesions. By the end of the year, we were beginning to believe that cyclosporine was indeed going to be a useful immunosuppressive strategy. The Institutional Review Board at Stanford gave us approval for an initial patient. However, the FDA had not approved the use of the drug for this indication, and this was the major stumbling block before going ahead with the procedure.

Early in 1981, Mary was becoming desperate about her condition. When she heard that we were awaiting FDA approval, she called the editor of her newspaper, who had contacts within the Arizona congressional offices. Through the intervention of an Arizona senator, we soon received a positive response from the FDA. After this happened, Mary moved from Arizona to Palo Alto to be near the center until a suitable donor was identified. Inasmuch as lung preservation remained an unresolved question, we would again need to transport donors to the center at the time of the operation and harvest organs in the adjoining operating room. Mary waited about 6 weeks until an excellent potential donor was identified in Southern California, and arrangements were made to transport to Stanford.

Needless to say, there was both excitement and anxiety as we made preparations for something that we had been working on in the laboratory over the past 5 years. John Wallwork was the transplant fellow at that time, and he and I worked hand-in-hand throughout the arrangements, the operation, and the postoperative care of Mary and of subsequent patients.

As is often customary, the actual transplant operation began shortly after midnight of March 9, 1981, and proceeded exactly as we had learned the operation in many laboratory procedures. We were used to excising the heart and both lungs en bloc in the small monkeys, and this was done in this operation as well. Subsequently, we would remove the heart and then both lungs sequentially. Although this added a little bit of extra time, the lack of adhesions and the lack of troublesome bronchial collaterals facilitated the operation. The right atrium, right ventricle, and pulmonary artery were massively enlarged, and the specimen was quite dramatic, with a very tiny left ventricle attached at the septum to a huge right ventricular cavity. Mary had indeed been struggling, and our timing of the operation was very fortunate. As in the laboratory, we preferred the use of a polypropylene suture for all anastomoses, including the trachea, without any special wrapping of the anastomosis. We had become convinced of the utility of the coronaryto-bronchial collaterals that we had identified in the 
monkeys. This and the improved immunosuppression we believed would allow excellent healing. The donor organs had been harvested in an adjoining operating room by Drs Stinson and Philip Oyer. As shown in Figure 1, the operative team consisted of Dr Shumway, John Wallwork, and me with the Stanford residents and fellows, Connie Athanasuleas, Stuart Jamieson, Bill Baumgartner, and Alexander Giritsky, looking on. The appearance of the totally empty thorax was indeed a dramatic moment. I wondered whether this was really going to work out. The implantation went smoothly, the heart resuscitated quickly, and lung function was adequate immediately. We returned to the Cardiac Surgery Intensive Care Unit a little before 6:00 AM. The next few weeks were a blur of activity, and a lot of it was directed toward improving nutrition and physical therapy for rehabilitation. We relied on the use of transvenous endomyocardial biopsy for the diagnosis of cardiac rejection, thinking that this would be our major tool for the assessment of rejection of the total graft. Although we identified two rejection episodes and treated them with pulses of methylprednisolone (Solu-Medrol), it would only be several years later that it was clearly determined that asynchronous heart and lung rejection was more common and that it was more important to follow the pulmonary biopsy by means of serial bronchoscopy.

Finally, Mary made a steady improvement and was discharged from the hospital after 82 days. She remained in the local area until 6 months postoperatively, when she returned to her home in Mesa, Arizona, and eventually back to work at the Mesa Tribune.

The next patient was 30-year-old Chuck Walker from Binghamton, New York, who had Eisenmenger syndrome owing to an unrepaired large membranous ventricular septal defect; he also underwent successful heart-lung transplantation on May 1, 1981. Both he and Mary Gohlke were wonderful ambassadors for the potential for total lung and heart replacement and the field of transplantation in general. Mary lived for a little over 5 years, when, unfortunately, she died as a result of complications suffered after an accidental fall. She did not have any findings of chronic rejection in either her lungs or heart at the time of death. Her

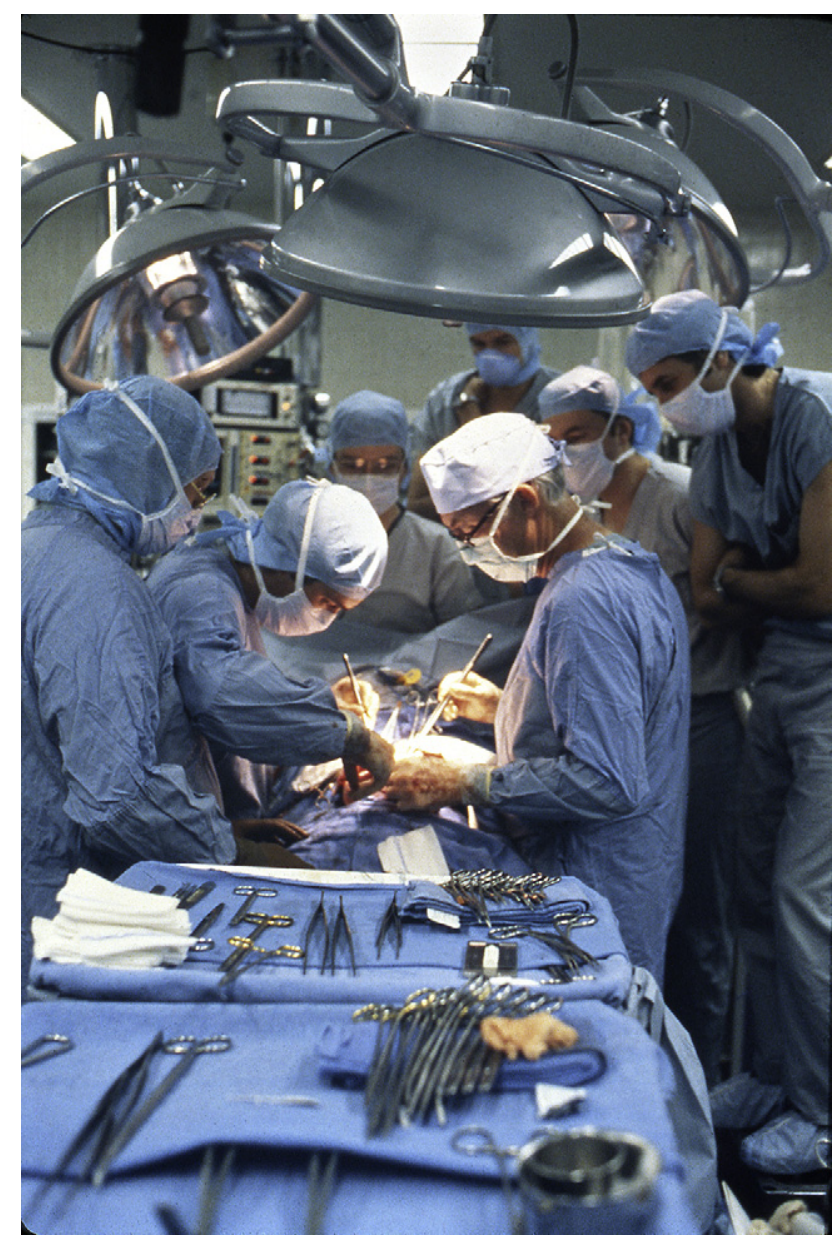

FIGURE 1. Stanford team at the first successful heart-lung transplant, March 9, 1981. At the operating table are Drs Shumway, Reitz, and Wallwork. Observing (from left to right) are Drs Athanasuleas, Jamieson, Baumgartner, and Giritsky.

spirit, courage, determination, and ultimately her willingness to explore the unknown in the face of many previous failures in human lung transplantation as a recipient of a combined heart-lung transplant, made possible the era of therapeutic lung transplantation. 